\title{
OPTIMALISASI POTENSI WISATA SEBAGAI UPAYA PEMBERDAYAAN MASYARAKAT DI DESA PESANGGARAHAN KECAMATAN MONTONG GADING
}

\author{
Muhammad Fadjri1, B. Fitri Pebrianti R.P2, Debby Sagita Putri3 \\ 1Pendidikan Bahasa Inggris, FKIP, Universitas Mataram \\ 2llmu Tanah, Fakultas Pertanian, Universitas Mataram \\ 3Agroekoteknologi, Fakultas Pertanian,Universitas Mataram \\ *Co-Author : baiqfitripebrianti@gmail.com
}

\begin{abstract}
ABSTRAK. Kuliah Kerja Nyata (KKN) merupakan salah satu bentuk pengabdian mahasiswa perguruan tinggi kepada masyarakat. Mahasiswa terlibat secara aktif dan kreatif melakukan pengembangan terhadap suatu desa lewat pembimbingan, pemberdayaan, juga menyadarkan masyarakat akan potensi desa yang dimiliki. Observasi dilakukan dengan metode: (1) tanya jawab, (2) dokumentasi, dan (3) survey langsung ke lapangan sehingga berdasarkan hasil observasi dapat ditentukan program kerja KKN. Desa Pesanggrahan secara administratif masuk ke wilayah Kecamatan Montong Gading Kabupaten Lombok Timur. Desa Pesanggrahan menjadi desa yang memiliki potensi alam yang mampu dijadikan sebagai objek wisata untuk pengembangan desa. Namun, sampai saat ini masih terdapat objek-objek wisata yang masih terisolasi dan belum diketahui keberadaannya oleh wisatawan salah satunya adalah Joben Eco Park. Kurangnya promosi yang dilakukan membuat objek wisata Joben Eco Park seperti tenggelam. Program mahasiswa KKN Universitas Mataram Mengenai Program Pemberdayaa Masyarakat terkhusus dibidang wisata di Desa Pesanggrahan melakukan berbagai upaya guna mengembangkan desa wisata Pesanggrahan. Program kerja utama yaitu, renovasi pintu gerbang camping ground yang berlokasi di Joben Eco Park dan pemanfaatan TIK (Penggunaan media sosial sebagai media informasi dan promosi objek wisata Joben Eco Park). Disamping itu, terdapat beberapa program kerja tambahan yaitu: (1) melakukan kerja sama dengan BKKBN mengembangkan kampung KB di Desa Pesanggrahan dengan melakukan pengecatan tembok di sepanjang jalan dan pembuatan plang "Delapan Fungsi Keluarga" di secretariat kampung KB Bunga Anggrek, (2) membersihkan dan memperindah akses menuju Joben Eco Park, (3) pembuatan dan pemasangan papan tanda arah menuju Joben Eco Park, mengadakan kegiatan "Smart House Education" bimbingan belajar dan mengaji, (4) bersama-sama dengan masyarakat melakukan gotong royong pembersihan jalan dan waduk di Desa Pesanggrahan. Oleh karena itu, adanya berbagai program kerja KKN dapat membantu mengembangkan potensi wisata Desa Pesanggrahan.
\end{abstract}

Kata Kunci: Joben Eco Park, Desa Pesanggrahan, KKN

ABSTRACT. Kuliah Kerja Nyata $(K K N)$ is a form of college student dedication to the community. Students actively and creatively develop the development of a village through mentoring, empowerment, also aware of the community of potential village owned. Observation is done by method: (1) question and answer, (2) documentation, and (3) direct survey to the field so that based on observation result can be determined KKN work program. Pesanggrahan Village administratively entered the district of Montong Gading East Lombok Regency. Pesanggrahan 


\begin{abstract}
Village becomes a village that has natural potential that can be used as a tourist attraction for village development. However, until now still there are tourist objects that are still isolated and yet to be known existence by tourists one of them is Joben Eco Park. The lack of promotion made the Joben Eco Park attraction like drowning. University of Mataram students program about the community Program, the most specialized in the field of tourism in the village Pesanggrahan make various efforts to develop the tourism village of Pesanggrahan. The main work Program is the renovation of the Camping ground gate located in Joben Eco Park and the utilization of ICT (use of social media as information media and promotion of Joben Eco Park tourist attraction). In addition, there are several additional work programs: (1) cooperate with $B K K B N$ to develop KB village in Pesanggrahan village by doing wall painting along the road and making Plang "eight family function" at the secretariat of KB Bunga Anggrek Village, (2) to clean and beautify access to Joben Eco Park, (3) the creation and installation of signs to Joben Eco Park, conducting "Smart House Education" activities tutoring and studying, (4) together with the community doing the cleaning of roads and reservoirs in Pesanggrahan village. Therefore, the existence of various KKN work programs can help to develop the tourism potential of Pesanggrahan village.
\end{abstract}

Keyword: Joben Eco Park, Pesanggrahan village, KKN

\title{
PENDAHULUAN
}

Desa Pesanggrahan secara administratif termasuk wilayah Kecamatan Montong Gading Kabupaten Lombok Timur,merupakan daerah yang terletak di daerah kawasan Perbukitan dengan kondisi pertanahan berbukit-bukit dan berbatasan langsung dengan Lereng Gunung Rinjani. Dengan luas wilayah $\pm 547.000 \mathrm{Ha} / \mathrm{m}_{2}$ ketinggian tanah $700 \mathrm{~m}$ diatas permukaan laut.Hal tersebut menyebabkan Desa Pesanggrahan memiliki suhu udara yang tergolong dingin tiap tahunnya yaitu rata-rata sebesar $27 \circ \mathrm{C}$.

Desa Pesanggrahan menjadi desa yang memiliki potensi alam yang mampu dijadikan sebagai objek wisata untuk pengembangan desa. Terdapat banyak objek-objek wisata salah satunya adalah Joben Eco Park. Joben Eco Park sendiri terletak tepat dibelakang pemandian joben. Namun, sampai saat ini objek wisata Joben EcoPark masih belum banyak dikenal dan diketahui keberadaannya oleh wisatawan Kurangnya promosi yang dilakukan membuat objek wisata Joben Eco Park seperti tenggelam dibalik ramainya pemandian Joben.

Program mahasiswa KKN Universitas Mataram Mengenai Program Pemberdayaan Masyarakat terkhusus dibidang wisata di Desa Pesanggrahan berupaya membantu dalam melakukan pengembangan wisata Joben Eco Park di desa wisata Pesanggrahan.

\section{ANALISIS PERMASALAHAN}

Desa Pesanggrahan dilihat dari sudut pandang ekonomi berfungsi sebagai lumbung tenaga kerja. Desa Pesanggrahan berfungsi sebagai daerah agraris dimana mayoritas penduduk adalah petani, pengrajin, peternak sehingga dapat menunjukan perkembangan baru yaitu timbulnya industri-industri kecil di daerah pedesaan, misalnya pengrajin anyaman, munculnya usaha-usaha kecil mandiri,terbentuknya beberapa kelompok pengrajin anyaman bambu dan lainnya. Apabila dilihat prospek kedepan Desa Pesanggrahan termasuk daerah yang perlu dikembangkan, mengingat daerah tersebut sangat berpotensi dan mempunyai nilai komersial yang cukup tinggi terutama dari hasil pertanian. Bantuan dan dukungan pemerintah dalam hal ini sangat di harapkan 
demi kemajuan seta pengembangan potensi masyarakat terutama dalam mencukupi kebutuhan rumah tangga. Terlebih lagi jauh adanya bantuan pemasaran produk-produk yang telah dihasilkan. Desa Pesanggrahan adalah kawasan perbukitan yang mayoritas mata pencaharian masyarakat adalah petani, yang dengan sendirinya memanfaatkan lahan pertanian yang dimilikinya antara lain, padi, sayuran, palawija.

Berdasarkan tingkat pertumbuhan ekonomi dari tahun ketahun dapat dikatakan berkembang. Hal ini dapat di lihat bahwa dalam rangka mencukupi kebutuhan hidup tidak hanya mengandalkan dari produksi pertanian, peternakan dan kerajinan, tetapi dapat dilihat pula dari kemauan masyarakat dalam mencukupi kebutuhan hidupnya dari berdagang dan menjadi pegawai swasta. Hal tersebut sangat membantu dalam rangka peningkatan kesejahteraan masyarakat pada umumnya (Arsip Desa Pesanggrahan, 2019)

\section{SOLUSI YANG DITAWARKAN}

Solusi yang ditawarkan adalah sebagai berikut:

1. Observasi tentang potensi desa.

Dilakukan dengan melakukan wawancara dengan pihak terkait, dokumentasi, danterjun langsung kelapangan guna mengetahui keadaan di lapangan

2. Membuat rancangan terhadap objek yang akan dibuat

3. Persiapan alat dan bahan

4. Penerapan dilapangan dengan dibantu oleh masyarakat.

\section{HASIL DAN PEMBAHASAN}

Berdasarkan hasil survey dengan melihat besarnya potensi wisata yang dimiliki oleh Desa Pesanggrahan dan melihat permasalahan yang terjadi di tengah masyarakat oleh karena itu, kami menyusun dan melaksanakan beberapa program kerja baik program kerja utama maupun tambahan.

\section{Renovasi dan Pembuatan Gerbang Camping Ground di Joben Eco Park (Proker Utama)}

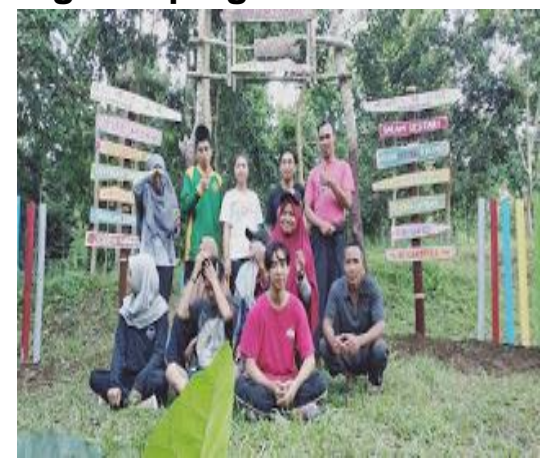

Gambar 1. Mahasiswa KKN dibantu oleh masyarakat menyelesaikan Proker Utama

Renovasi dan pembuatan gerbang camping ground dilakukan oleh mahasiswa KKN dibantu oleh masyarakat. Renovasi dilakukan dikarenakan tampilan gerbang yang sangat sederhana dan sudah tak menarik lagi. Diharapkan dengan direnovasinya gerbang camping ground tersebut membuat tampilan Joben Eco Park makin menarik dan wisatawan yang berkunjung makin tertarik.

Pemanfaatan TIK (Penggunaan media sosial sebagai media informasi dan promosi objek wisata Joben Eco Park (Proker utama) 




Gambar 2. Tampilan media sosial Joben Eco Park

Di era globalisasi sekarang ini, teknologi informasi berperan sangat penting. Dengan menguasai teknologi dan informasi, kita memiliki modal yang cukup untuk menjadi pemenang dalam persaingan global. Media sosial digunakan sebagai alat promosi karena memiliki respon secara langsung dengan penggunanya. Sudah mulai banyak bermunculan akun di media sosial yang digunakan untuk memasarkan suatu produk secara lebih luas. Oleh karena itu, mahasiswa KKN bekerja sama dengan pihak KMPH mengembangkan akun media social berupa akun Facebook yang dapat digunakan untuk mempromosikan wisata Joben Eco Park.

Pembuatan Papan Penjurusan Menuju JEP ( Joben Eco Park) \& Kampung KB Bunga Anggrek

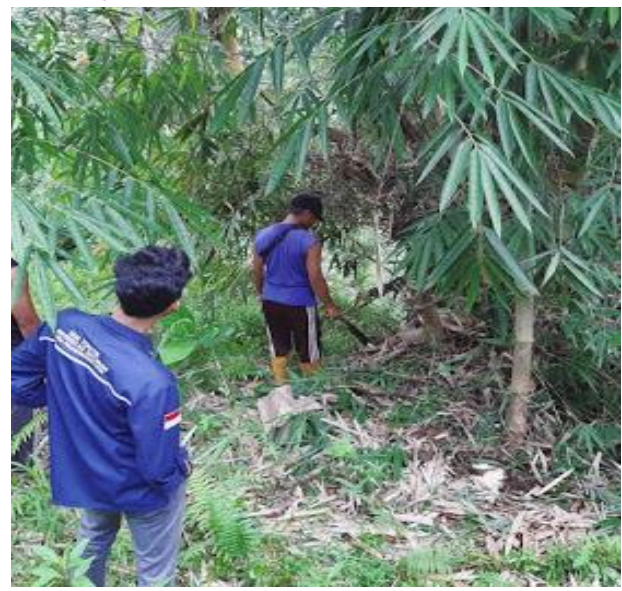

Gambar 3. Mahasiswa KKN dibantu oleh warga mencari bambu petung dikawasan Joben Eco Park

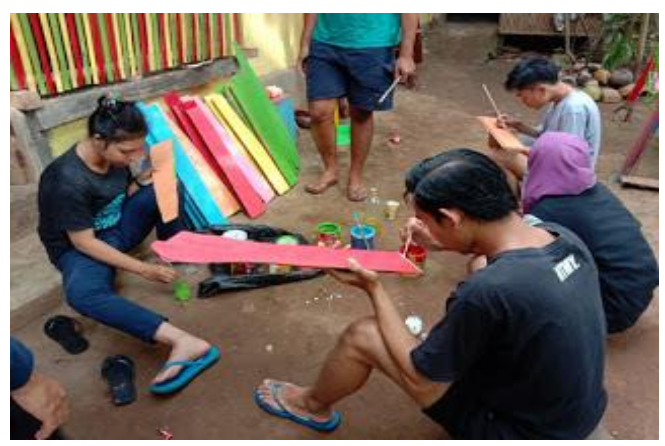

Gambar 4. Mahasiswa KKN sedang melakukan pengecatan papan penunjuk arah 


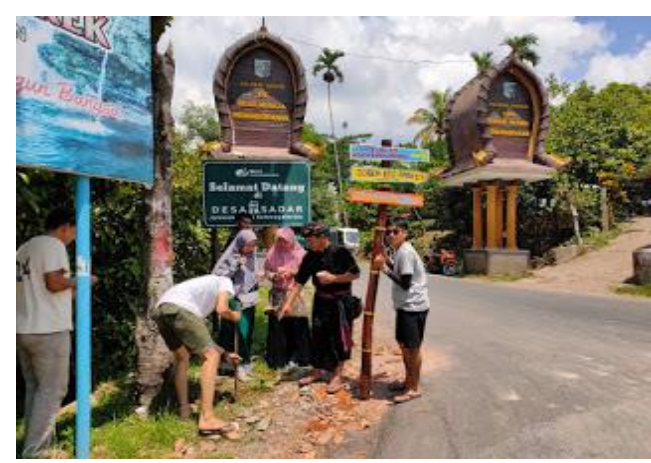

Gambar 5. Mahasiswa KKN bersama Kades dan Kawil melakukan pemasangan tanda arah

Pembuatan tanda arah bertujuan agar wisatawan lokal maupun asing yang berkunjung ke Desa Pesanggrahan dapat mengetahui jalur-jalur penunjuk arah menuju ke tempat wisata. Penggunaan bahan dasar bambu petung dan kayu bekas digunakan sebagai bahan pembuatan gerbang camping ground di Joben Eco Park dan tanda arah. Keberadaan penunjuk arah di desa ini sebelumnya sangat minim sehingga menyebabkan banyak wisatawan kadang kali tersesat. Kegiatan ini langsung di dampingi oleh Kepala Desa Pesanggrahan yakni $\mathrm{H}$. Badrun dan salah satu Kepala Wilayah Pesanggrahan yakni Bapak Warokal.

\section{Membersihkan jalan menuju Joben Eco Park}

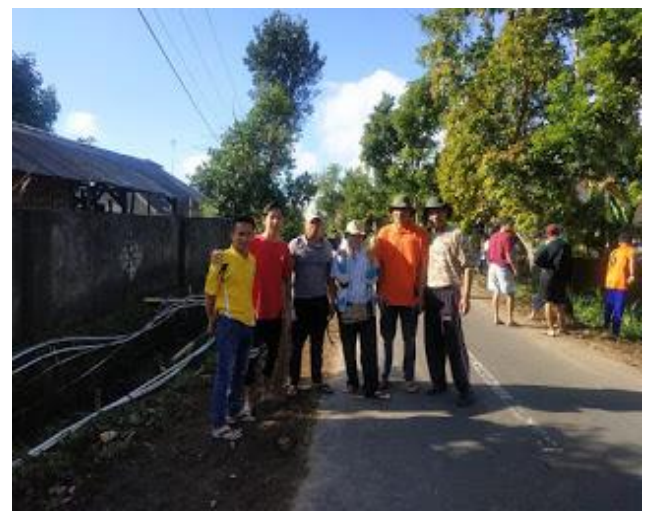

Gambar 6. Mahasiswa KKN bersama beberapa kadus foto bersama saat pembersihan jalan

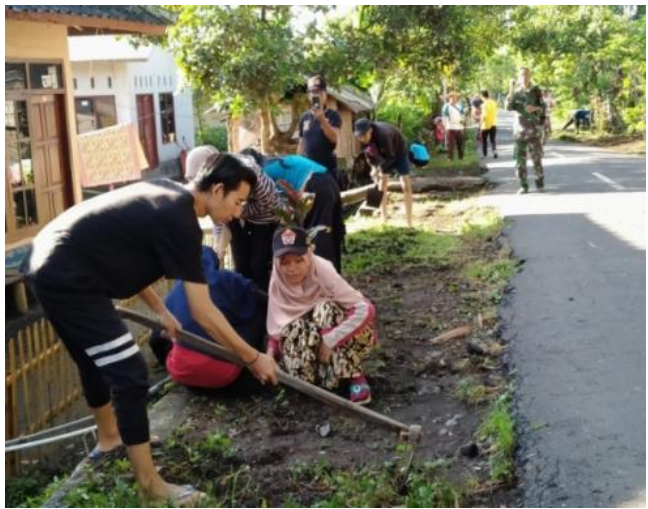

Gambar 7. Mahasiswa KKN melakukan pembersihan ruas jalan menuju Joben Eco Park 
Kegiatan pembersihan jalan menuju tempat wisata Joben Eco Park merupakan salah satu program kerja tambahan dari Mahasiswa KKN Tematik Unram sebagai bentuk patisipasi dalam rangka membersihkan juga memperindah ruas jalan menuju ke Joben Eco Park. Bertujuan untuk memperindah akses jalan menuju tempat wisata yakni JEP ( Joben Eco Park).

Penanaman bibit pohon disekitar jalan menuju Joben EcoPark

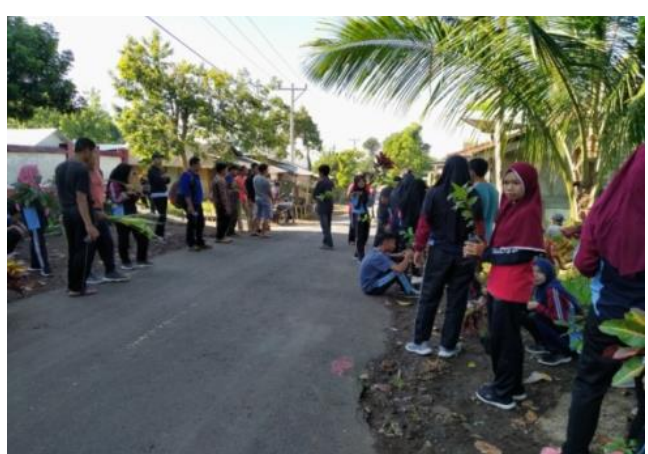

Gambar 8. Penanaman bibit pohon bersama masyarakat dan siswa SMAN 1 Montong Gading

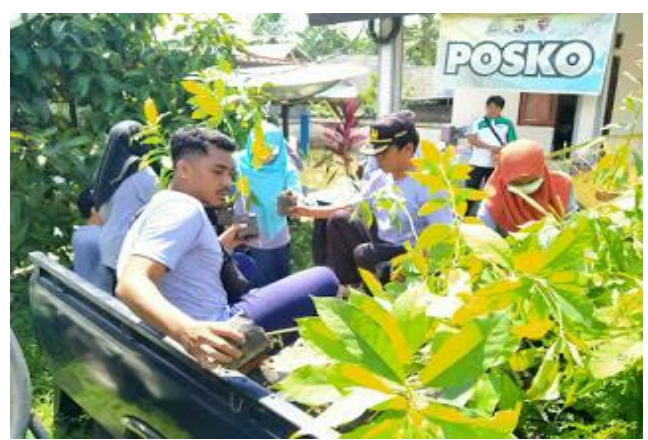

Gambar 9. Pengambilan Bibit Pohon dari kantor di KPH ( Kesatuan Pemelihara Hutan)



Gambar 10. Kades Pesanggrahan membantu melakukan penanaman bibit pohon 


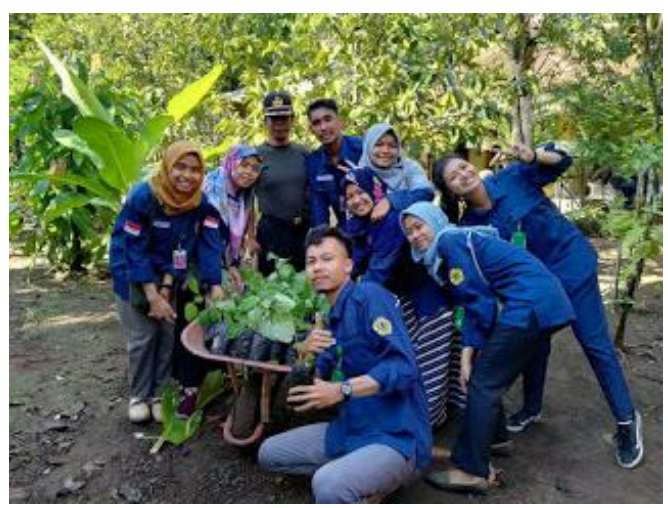

Gambar 11. Mahasiswa KKN bersama Kades dan kadus melakukan penanaman bibit pohon.

Kegiatan ini merupakan ajang dalam memperindah jalan menuju Joben Eco Park.Kegiatan penanaman bibit pohon bekerja sama dengan pihak desa, $\mathrm{KPH}$ (Kesatuan Pemelihara Hutan), siswa SMAN 1 Montong Gading, dan juga masyarakat. Bibit pohon yang digunakan yaitu jati putih, alpukat, sengon, dan nangka. Beberapa kegiatan yang dilakukan sebagai berikut :

1. Menanam bibit pohon disepanjang jalan menuju JobenEco Park

2. Membagikan bibit pohon tersebut kepada masyarkat Desa Pesanggrahan sebagai bentuk partisipasi dalam memperindah dan melestarikan alam.

Pengecatan tembok dan Pembuatan Bagan Delapan Fungsi Keluarga di Kampung KB Bunga Anggrek Dusun Solong Lauk Desa Pesanggrahan.

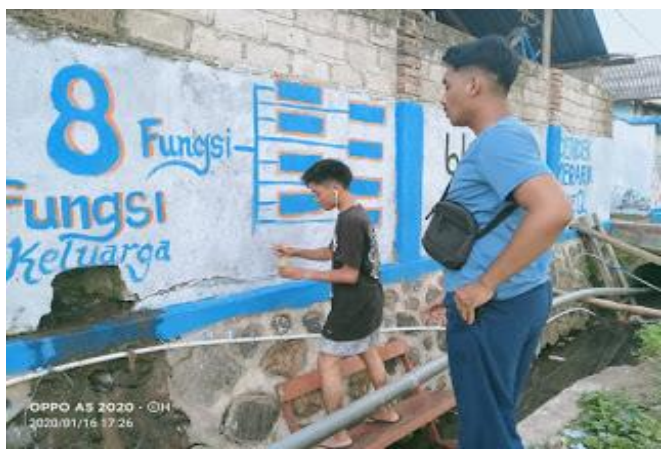

Gambar 12. MahasiswaKKN sedang melakukan pengecatan

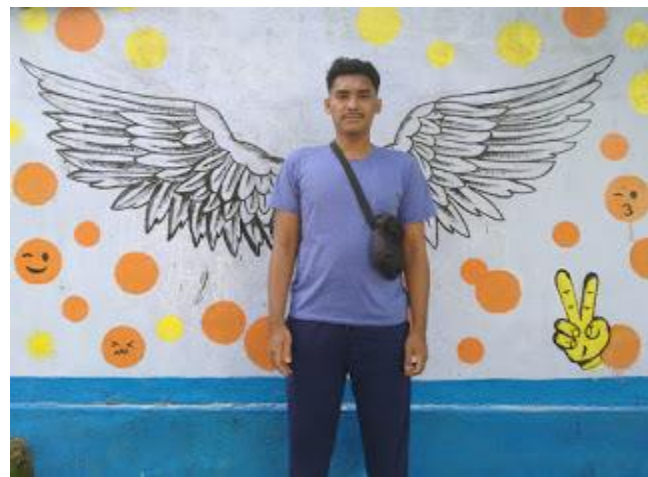

Gambar 13. Mahasiswa berfoto didepan salah satu objek foto baru di Kampung KB 


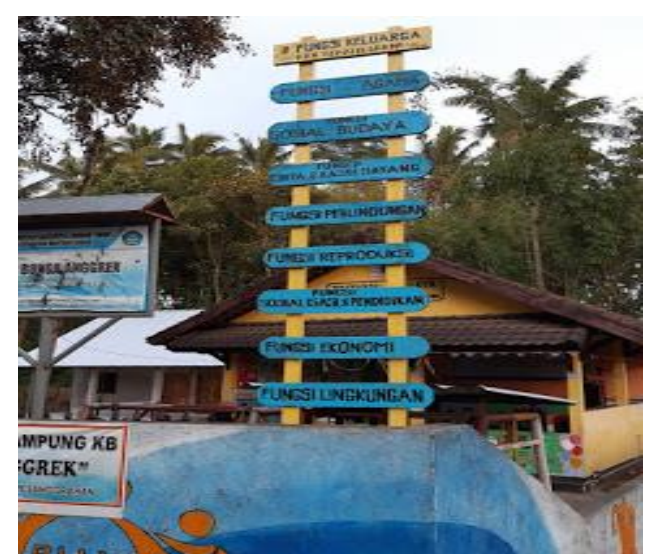

Gambar 14. Tampilan bagan "Delapan Fungsi Keluarga”

Kegiatan Proker Tambahan KKN Tematik di Desa Pesanggrahan Desa Pesanggrahan kali ini melakukan kerja sama dengan pihak BKKBN dengan melakukan pengecatan dengan tema Kampung KB guna memperindah dinding-dinding warga. Kegiatan langsung di pantau oleh Kepala Desa Pesanggrahan Bapak $\mathrm{H}$. Badrun dan dibantu oleh beberapa warga di Desa Pesanggrahan khususnya di Dusun Solong Lauk. Kegiatan kedua di Kampung KB ini yaitu membuat bagan "Delapan Fungsi Keluarga" yang dipasang tepat didepan Sekretariat Kampung KB Bunga Anggrek. Kampung KB dibentuk untuk meningkatkan kualitas hidup masyarakatnya dan menjadikan kampung KB sebagai Kampung wisata yang sejalan dengan program pemerintah.

\section{Smart House Education}

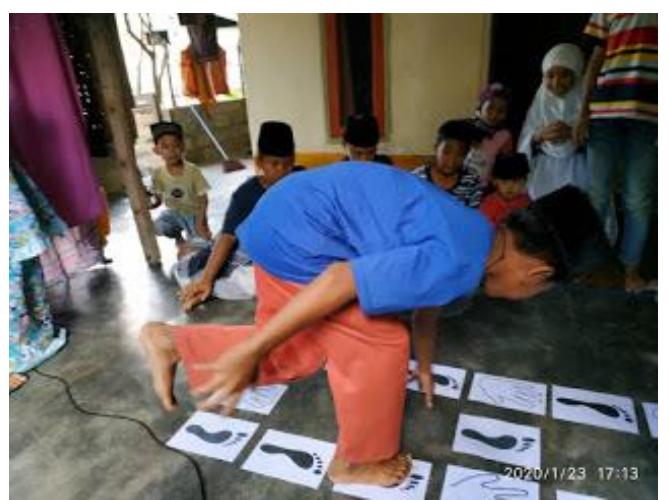

Gambar 15. Proses pembelajaran yang asyik dan menyenangkan.

Bimbingan belajar Smart House Education adalah tata cara belajar dengan mengedepankan kenyamanan dan pahaman siswa terhadap materi yg disampaikan, sehingga kami sebagai mahasiswa KKN Tematik UNRAM membuat sistem kelas semi private dimana ruangan atau wadah tempat belajar bersama ini hanya di isi maksimal 15 orang dan 1 tutor. Sistem ini diharapkan agar teman-teman kami yang memiliki keahlian dalam bidang keguruan baik dalam tingkat Paud, SD, SMP dan SMA dapat lebih dekat dengan siswa/siswi tersebut, dan membantu memahami materi dengan cara pendekatan satu persatu. Dengan adanya kegiatan ini para siswa atau siswi tersebut dapat lebih mudah menangkap dan memahami pelajaran yang ada di sekolah mereka serta lebih disiplin dalam mengerjakan PR (HomeWork) dan disiplin dalam menghargai waktu. Kegiatan Smart House Education tidak hanya terfokus dalam bidang akademisi saja melainkan kami juga 
memberikan pendidikan dalam segi Agama (Religius) kepada siswa seperti mengaji baik dari tingkat lqra sampai Al-Quraan.

\section{KESIMPULAN}

Program kerja kelompok KKN di Desa Pesanggrahan dengan tema"Optimalisasi potensi wisata sebagai upaya pemberdayaan masyarakat di Desa Pesanggarahan Kecamatan Montong Gading" berjalan dengan baik. Hal ini terlihat dari partisipasi dan ketertarikan masyarakat Desa Pesanggrahan yang antusias mengikuti beberapa kegiatan program kerja. Program kerja yang sukses terlaksana yaitu renovasi pintu gerbang camping ground yang berlokasi di Joben Eco Park dan pemanfaatan TIK (Penggunaan media sosial sebagai media informasi dan promosi objek wisata Joben Eco Park). Disamping itu, terdapat beberapa program kerja tambahan yang juga sukses terlaksana yaitu: (1) melakukan kerja sama dengan BKKBN mengembangkan kampung KB di Desa Pesanggrahan dengan melakukan pengecatan tembok di sepanjang jalan dan pembuatan plang "Delapan Fungsi Keluarga" di secretariat kampung KB Bunga Anggrek, (2) membersihkan dan memperindah akses menuju Joben Eco Park, (3) pembuatan dan pemasangan papan tanda arah menuju Joben Eco Park, mengadakan kegiatan "Smart House Education" bimbingan belajar dan mengaji, (4) bersama-sama dengan masyarakat melakukan gotong royong pembersihan jalan dan waduk di Desa Pesanggrahan. Terlaksananya program kerja KKN diharapkan mampu memperbaiki dan mengembangkan potensi wisata yang ada di Desa Pesanggrahan.

\section{REFERENSI}

Nukman, H. (2019). Ada Tempat Seru di Kaki Gunung Rinjani, https://travel.detik.com/travel-news/d4751904/ada-tempat-seru-di-kaki-gunung-rinjani, diakses 8 Februari 2020

Safira, P. (2018). Pemanfaatan Media Sosial sebagai Media Promosi Baru dalam Usaha Kuliner, https://www.kompasiana.com/putrynadiasafira3957/5b4df89f6ddcae2eb669c112/pemanfaatanmedia-sosial-sebagai-media-promosi-baru-dalam-usaha-kuliner?page=all, diakses 8 Februari 2020 